\title{
State-dependent alteration in face emotion recognition in depression
}

Ian M. Anderson, Clare Shippen, Gabriella Juhasz, Diana Chase, Emma Thomas, Darragh Downey, Zoltan G. Toth, Kathryn Lloyd-Williams, Rebecca Elliott and J. F. William Deakin

\section{Background}

Negative biases in emotional processing are well recognised in people who are currently depressed but are less well described in those with a history of depression, where such biases may contribute to vulnerability to relapse.

\section{Aims \\ To compare accuracy, discrimination and bias in face emotion recognition in those with current and remitted depression.}

\section{Method}

The sample comprised a control group $(n=101)$, a currently depressed group $(n=30)$ and a remitted depression group $(n=99)$. Participants provided valid data after receiving a computerised face emotion recognition task following standardised assessment of diagnosis and mood symptoms.

\section{Results}

In the control group women were more accurate in recognising emotions than men owing to greater discrimination. Among participants with depression, those in remission correctly identified more emotions than controls owing to increased response bias, whereas those currently depressed recognised fewer emotions owing to decreased discrimination. These effects were most marked for anger, fear and sadness but there was no significant emotion $\times$ group interaction, and a similar pattern tended to be seen for happiness although not for surprise or disgust. These differences were confined to participants who were antidepressant-free, with those taking antidepressants having similar results to the control group.

\section{Conclusions}

Abnormalities in face emotion recognition differ between people with current depression and those in remission. Reduced discrimination in depressed participants may reflect withdrawal from the emotions of others, whereas the increased bias in those with a history of depression could contribute to vulnerability to relapse. The normal face emotion recognition seen in those taking medication may relate to the known effects of antidepressants on emotional processing and could contribute to their ability to protect against depressive relapse.

\section{Declaration of interest}

I.M.A. and J.F.W.D. have received grants and honoraria from pharmaceutical companies that manufacture antidepressant and antipsychotic drugs (Astrazeneca, Servier) not related to the research described here.
The recognition of basic facial emotions (anger, disgust, fear, happiness, sadness, surprise) is a universal and innate ability in humans, ${ }^{1}$ and involves brain structures concerned with perceptual analysis (occipital and temporal cortex) and those related to emotional processing including the amygdala, hippocampus, basal ganglia, insula and orbitofrontal cortex. ${ }^{2}$ Face emotion recognition is involved in social communication and requires the ability to link face perception with knowledge about the emotion signalled. The recognition of emotions is believed to use neural pathways in common with those used to generate facial emotions, and probably to experience emotions. ${ }^{2}$

Negative emotional biases in people with depression include an attentional bias toward negative emotional cues and away from positive cues, and an enhanced memory for negative emotional material. $^{3}$ There is general agreement that face emotion recognition is altered in depression, ${ }^{3}$ but results are somewhat inconsistent; reduced recognition of positive and/or negative valence are the most common findings. ${ }^{4-6}$ Although abnormal emotional processing is thought to be a vulnerability factor for depressive relapse, ${ }^{7}$ little is known about face emotion recognition in people who have recovered from depression, with two small studies reporting increased recognition of single - but different - negative face emotions. ${ }^{8,9}$ It has recently been proposed that antidepressants act to normalise negative emotional bias, ${ }^{10}$ with improvement in mood argued to occur as a result of this change in emotional processing. In this study we examined face emotion recognition in participants with depression, either current or in remission, compared with a control group. Our hypothesis was that people with current depression would have impaired emotion recognition, particularly for happiness, and that those whose depression was in remission would have normal recognition of happiness but a bias towards identifying negative emotions.

\section{Method}

Participants in this study came from a larger UK population sample of 2004 participants recruited from two primary care practice lists and a website (http://www.newmood.co.uk) which was enriched with those with a history of depression. A subgroup, supplemented with further recruits through the website and from psychiatric out-patient clinics, undertook a standardised interview, personality and mood questionnaires and neuropsychological testing between March 2006 and March 2008. The aim was to recruit 250 participants divided evenly between three groups: controls, people currently depressed and people with a history of depression but currently in remission (the 'remitted depressed' group). The study was approved by the local research ethics committees and was carried out in accordance with the Declaration of Helsinki. All participants gave written informed consent after receiving a full explanation of the study.

\section{Participants}

Following telephone screening, 278 people were interviewed using the Structured Clinical Interview for DSM-IV, ${ }^{11}$ resulting in 
246 people who met the inclusion criteria. Common reasons for exclusion were the presence of other psychiatric disorders and partial remission of depression. Participants were required to be aged 18-60 years and in good physical health. Control group participants were required to be without a personal history of psychiatric disorder or a family history of treated depression; currently depressed participants needed to meet criteria for a current major depressive episode; and those in the remitted depressed group were required to be in full remission with no other current psychiatric disorder, a history of at least two prior major depressive episodes (one lasting at least 2 months) and a Montgomery-Åsberg Depression Rating Scale (MADRS) score of less than $13 .{ }^{12}$ Exclusion criteria for all groups were current or past physical illness or debilitating physical condition; current alcohol or drug dependence or harmful use; a history of bipolar affective disorder, psychosis, dementia or mental impairment; and taking medication that might interfere with neuropsychological function (apart from antidepressants, antipsychotics or lithium in the case of patients with depression). Depressed participants could meet criteria for a comorbid anxiety disorder provided this had not pre-dated the primary diagnosis of major depressive disorder. Depressive and anxiety symptoms were assessed using the MADRS, a ten-item observer-rated scale, and the Clinical Anxiety Scale (CAS), a six-item observer-rated scale derived from the Hamilton Anxiety Scale. ${ }^{13}$ The participants' IQ was estimated using Ammons' Quick Test. ${ }^{14}$

\section{Face emotion recognition task}

The face emotion recognition task was adapted from the task developed by Harmer et al. ${ }^{15}$ The task assesses participants' ability to correctly recognise different facial expressions of anger, disgust, fear, happiness, sadness and surprise at different intensities based on the Ekman \& Friesen faces. ${ }^{16}$ Using morphing software the intensity of each emotion can be varied between $0 \%$ (neutral) and $100 \%$ (full emotion); for this study we chose a neutral expression and three intensities for each emotion (30\%, 50\% and $70 \%$ ) based on our previous experience showing that this encompasses the range of sensitivity for most individuals. Four actors (two men, two women) were used for each emotion, giving 76 images in total ( 12 for each emotion and 4 neutral) presented in a pseudorandom order for intensity, emotion and actor. Images were presented on a personal computer with adjacent keys labelled with the six emotions and neutral. In order to familiarise participants with the task, three trial blocks containing each emotion at $100 \%$ were at shown (without specifically identifying the emotion). Images were initially shown for $2.0 \mathrm{~s}$ each, shortening with each block until matching the $1.0 \mathrm{~s}$ presentation time in the task itself. The intertrial interval was $4.5 \mathrm{~s}$, giving a total task duration of just under $7 \mathrm{~min}$.

The data analysed were the number of correct identifications in total, and at each level of intensity, for each emotion (accuracy), the number of false positives (false alarms) for each emotion and the reaction time taken to respond to each emotion correctly identified. Failure to respond was taken as an incorrect identification. Signal detection analysis was applied to the data in order to examine whether group differences in accuracy were due to altered discrimination or to response bias, which can independently influence the number of correct identifications. ${ }^{17}$ The ability to discriminate individual emotions was measured using the discriminability index $\left(d^{\prime}\right)$, calculated as $z \mathrm{FA}-z \mathrm{HR}$, where $z$ is the inverse of the standard normal cumulative distribution (i.e. $z$-scores corresponding to right-tail $P$-values), FA is the false-alarm rate (the proportion of incorrect identifications of an emotion when other emotions or neutral expressions were presented) and $\mathrm{HR}$ is the hit rate for each emotion (the proportion of correct identifications for that emotion). In order to allow calculation, when there was no incorrect identification the value was taken as 0.5 , and when all 12 instances of an emotion were identified, 0.5 was subtracted, using the correction by Macmillan \& Creelman. ${ }^{16}$ The discriminability index in this study is principally the ability to discriminate a specific emotion. (The false-alarm rates analysed by group and emotion are reported in online Table DS2.)

Response bias was measured using 'criterion', calculated as $-1 / 2(z \mathrm{HR}+z \mathrm{FA})$, with higher values (conservative responding or reduced bias) indicating a generally reduced tendency to identify emotions with both lower false-alarm and lower hit rates. Lower criterion values (liberal responding or increased bias) reflect a greater tendency to identify emotions, resulting in both higher hit and false-alarm rates.

\section{Statistical analysis}

Analysis was carried out using SPSS version 15.0 for Windows. Given that the groups differed in age and gender distribution, the effects of these variables were examined in the control group. The effects of age on face emotion recognition measures were examined by Pearson's product moment correlation against the sum of the correctly recognised emotions and also by correlation against each emotion separately. The effect of gender was tested with a repeated-measures analysis of covariance (ANCOVA) with emotion as a within-individual factor and gender as a betweengroup factor with age as a covariate and Greenhouse-Geisser correction applied (for clarity, uncorrected degrees of freedom are reported). Post hoc testing was carried out using least significant difference; unpaired $t$-tests were used to test the effects in individual emotions which are only illustrative in the absence of a gender $\times$ emotion interaction.

The primary analysis of the effect of group (control, currently depressed, remitted depressed) on face emotion recognition measures was examined using repeated-measures ANCOVA with emotion as a within-individual factor and group as a betweenindividual factor. The effect of medication was examined as a secondary analysis. Age and gender were entered as covariates and Greenhouse-Geisser correction applied. Gender was included as a covariate and not as a between-group factor because the proportions of men and women were not equal between groups; however, an exploratory ANCOVA with gender as a betweengroup factor did not show any group $\times$ gender or emotion $\times$ group $\times$ gender interaction indicative of differential gender effects. The results for men and women separately are available in online Table DS4. Given the interest in individual emotions the effect of group on each emotion was also carried out using analysis of covariance under the general linear model with age and gender entered as covariates. These are not reported in the absence of significant emotion $\times$ group interactions but are illustrated in Fig. 1 and in online Figs DS1-5. Post hoc testing was carried out using simple contrasts or least significant difference. Where there were differences between groups in identification of individual emotions, a repeated-measures ANCOVA, covaried for age and gender, was used to examine whether there was any differential effect of emotion intensity by group. These results are not reported because group effects were seen across the intensity range and did not add to the interpretation.

\section{Results}

For 16 participants the results from the face emotion recognition task were not available or were excluded because of technical problems or lack of understanding of the task, providing 230 


\begin{tabular}{|c|c|c|c|}
\hline & $\begin{array}{c}\text { Control group } \\
n=101\end{array}$ & $\begin{array}{l}\text { Current depression group } \\
\qquad n=30\end{array}$ & $\begin{array}{l}\text { Remitted depression group } \\
\qquad n=99\end{array}$ \\
\hline Age, years: mean (s.d.) & $30.3(10.1)$ & $38.6(10.9)^{\mathrm{a}}$ & $34.2(10.8)^{b}$ \\
\hline \multicolumn{4}{|l|}{ Gender } \\
\hline Female: male, $n$ & $58: 43$ & $22: 8$ & $79: 20$ \\
\hline Female, \% & 57 & 73 & $80^{\mathrm{a}}$ \\
\hline Education, years: mean (s.d.) & $16.2(2.5)$ & $14.5(3.0)^{a}$ & $16.3(2.7)^{C}$ \\
\hline Estimated IQ: mean (s.d.) & 96 (11) & $96(8)$ & $98(11)$ \\
\hline MADRS score: mean (s.d.) & $1.3(1.8)$ & $24.3(6.8)^{a}$ & $3.6(3.3)^{a, c}$ \\
\hline CAS score: mean (s.d.) & $0.6(1.0)$ & $10.3(4.1)^{\mathrm{a}}$ & $1.7(2.2)^{a, c}$ \\
\hline Previous depressive episodes: mean (s.d.) & 0 & $6.3(4.4)$ & $3.0(2.2)^{\mathrm{c}}$ \\
\hline \multicolumn{4}{|l|}{ Medication, $n(\%)$} \\
\hline No medication & $101(100)$ & $14(47)$ & $82(83)^{d}$ \\
\hline Antidepressants & $0(0)$ & $16(53)$ & $17(17)$ \\
\hline Antipsychotics & $0(0)$ & $4(13)$ & $0(0)$ \\
\hline Other medication & $0(0)$ & $1(3)^{\mathrm{e}}$ & $0(0)$ \\
\hline $\begin{array}{l}\text { CAS, Clinical Anxiety Scale; MADRS, Montgomery- } \\
\text { a. } P<0.01 \text { v. control group. } \\
\text { b. } P<0.05 \text { v. control group. } \\
\text { c. } P<0.01 \text { v. current depression group. } \\
\text { d. One person was taking St John's wort. } \\
\text { e. Zaleplon. }\end{array}$ & & & \\
\hline
\end{tabular}

participants for data analysis; their characteristics are shown in Table 1. There was slower recruitment of patients with current depression, resulting in fewer in this group. Women were overrepresented in both depression groups, in which the mean age was also higher, particularly in the current depression group. Participants with depression had fewer years in education but there was no group difference in estimated IQ. Six participants with depression (20\%) had a comorbid anxiety disorder (two with panic disorder, two with social phobia and one each with obsessive-compulsive disorder and post-traumatic stress disorder). Response rates for the task were high and did not differ between groups (controls 95.4\%, s.d. $=4.9$, current depression 95.8\%, s.d. $=3.2$, remitted depression $96.4 \%$, s.d. $=2.0 ; P=0.21$ ).

\section{Face emotion recognition in the control group}

For full ANCOVA results see online Table DS1. For accuracy of emotion recognition there was a significant effect of emotion $\left(F_{(5,490)}=18.844, P<0.001\right.$; Fig. 1) with happiness recognised most accurately and anger least. Women correctly recognised more emotions than men (corrected mean 6.3 v. 5.8; gender $\left.F_{(1,98)}=7.146, P=0.009\right)$ but there was no gender $\times$ emotion interaction $(P=0.56)$. Post hoc $t$-tests of individual emotions showed a significant difference for fear $(P=0.014)$ and a trend for anger $(P=0.078)$, with minimal differences for the positive emotions happiness and surprise (all $P \geqslant 0.2$ ). Women were slightly quicker to respond when identifying emotions overall (corrected means $2.06 \mathrm{~s}$ v. $2.21 \mathrm{~s}$ respectively; gender, $\left.F_{(1,91)}=4.040, P=0.047\right)$. There was a significant interaction between emotion and age $\left(F_{(5,490)}=4.396, P=0.001\right)$, with significant negative correlations between age and number of face emotions correctly recognised for sadness $(r=-0.22, P=0.025)$ and surprise $(r=-0.23$, $P=0.02)$ and a positive correlation with disgust $(r=0.31$, $P=0.002)$. For emotion discrimination $\left(d^{\prime}\right)$ the results were essentially the same as those seen for accuracy (online Table DS1): on post hoc $t$-tests women showed greater discrimination of anger $(P=0.015)$, fear $(P=0.024)$ and disgust $(P=0.018)$. Increasing age was associated with decreased discrimination of sadness $(r=-0.20, \quad P=0.043)$ and surprise $(r=-0.20$, $P=0.045$ ) but not disgust. For bias to identify emotions (criterion) only a significant effect of emotion was seen
$\left(F_{(5,490)}=9.032, P<0.001\right)$ with the least bias (highest criterion) for anger and disgust $(P<0.001 v$. other emotions $)$ and surprise having the greatest bias (lowest criterion) $(P<0.001 v$. other emotions) (online Table DS1). A significant interaction between emotion and age $\left(F_{(5,490)}=3.389, P=0.01\right)$ appeared to be accounted for by a greater bias (lower criterion) to identify disgust with increasing age $(r=-0.31, P=0.002)$. In summary, in the control group gender differences in the accuracy of identifying different emotions were accounted for by women showing slightly greater accuracy and discrimination than men, possibly more marked for negative than positive emotions. Age had a selective effect on emotion recognition; increasing age was associated with decreased discrimination of sadness and surprise and increased bias towards disgust.

\section{Face emotion recognition in depression}

Accuracy

Analysis of covariance showed significant effects of emotion $\left(F_{(5,1125)}=11.900, \quad P<0.001\right) \quad$ and group $\quad\left(F_{(2,225)}=5.340\right.$,
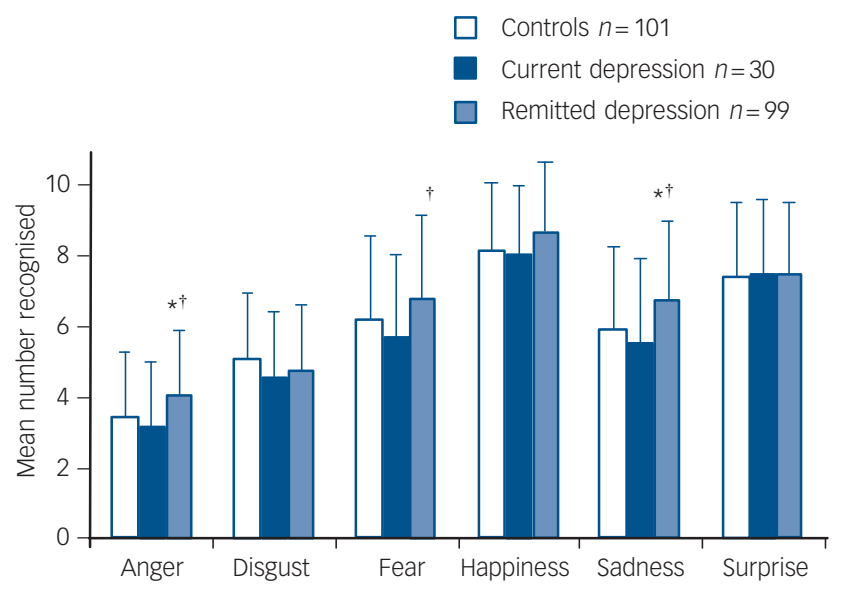

Fig. 1 Individual face emotion recognition accuracy categorised by group.

Values are age- and gender-corrected means plus standard deviations. ${ }^{*} P<0.05 \mathrm{~V}$. control group, ${ }^{\dagger} P<0.05 \mathrm{~V}$. current depression group. 
Table 2 Face emotion recognition parameters according to group

\begin{tabular}{|c|c|c|c|}
\hline & $\begin{array}{l}\text { Control group } \\
\qquad n=101 \\
\text { Mean (s.d.) }\end{array}$ & $\begin{array}{l}\text { Current depression group } \\
\qquad \begin{array}{l}n=30 \\
\text { Mean (s.d.) }\end{array}\end{array}$ & $\begin{array}{l}\text { Remitted depression group } \\
\qquad \begin{array}{l}n=99 \\
\text { Mean (s.d.) }\end{array}\end{array}$ \\
\hline Accuracy $^{b}$ & $6.10(1.06)$ & $5.76(1.10)$ & $6.42(1.04)^{c}$ \\
\hline Reaction time, s & $2.18(0.65)$ & $2.30(0.65)$ & $2.24(0.63)$ \\
\hline Discrimination $^{d}$ & $1.82(0.36)$ & $1.66(0.36)^{e}$ & $1.88(0.36)^{f}$ \\
\hline Bias $^{g}$ & $0.89(0.12)$ & $0.90(0.12)$ & $0.84(0.12)^{h}$ \\
\hline \multicolumn{4}{|c|}{$\begin{array}{l}\text { a. Values are corrected means and standard deviations. } \\
\text { b. Maximum possible score } 12 \text {. } \\
\text { c. } P<0.05 \mathrm{v} \text {. control group, } P<0.01 \mathrm{v} \text {. depressed group. } \\
\text { d. Discrimination } d^{\prime} \text { : higher values indicate greater discrimination. } \\
\text { e. } P<0.05 \mathrm{v} \text {. control group. } \\
\text { f. } P<0.01 \mathrm{v} \text {. depressed group. } \\
\text { g. Criterion }- \text { lower values indicate greater bias. } \\
\text { h. } P<0.01 \mathrm{v} \text {. control group, } P<0.05 \mathrm{v} \text {. depressed group. }\end{array}$} \\
\hline
\end{tabular}

$P=0.005)$ with no interaction between emotion and group $(P=0.17)$. The corrected mean number of emotions correctly recognised by controls was non-significantly more than those recognised by currently depressed participants but fewer than those recognised by participants in remission (Table 2, online Table DS3). The effect appeared to be mainly driven by the negative emotions anger, fear and sadness (see Fig. 1).

\section{Reaction time}

Analysis of covariance showed no significant effect of emotion $(P=0.39)$ or group $(P=0.77)$ but an interaction between emotion and group $\left(F_{(10,1050)}=2.475, P=0.009\right)$. There was no significant difference in reaction time between groups for all emotions taken together, although the currently depressed group was the slowest and the control group the fastest (Table 2). The emotion $\times$ group interaction appeared to be accounted for by the control group having slightly faster mean reaction times for happiness than the currently depression group $(1.94 \mathrm{~s} v .2 .06 \mathrm{~s}$, $P=0.22$ ) and the remitted depression group ( $2.07 \mathrm{~s}, P=0.06$ ), whereas the remitted depression group had slightly faster mean reaction times for sadness than the control group $(2.13 \mathrm{~s} v$. $2.26 \mathrm{~s}, P=0.07)$ and the currently depressed group $(2.30 \mathrm{~s}$, $P=0.11$ ).

\section{Discrimination $\left(d^{\prime}\right)$}

Analysis of covariance showed significant effects of emotion $\left(F_{(5,1125)}=27.024, \quad P<0.001\right)$ and group $\left(F_{(2,225)}=4.850\right.$, $P=0.009)$, with no interaction between emotion and group $(P=0.62)$. Currently depressed participants had reduced discrimination compared with controls and those with remitted depression (Table 2, online Table DS3). The pattern was seen broadly across the emotions (online Fig. DS1).

\section{Bias (criterion)}

Analysis of covariance showed significant effects of emotion $\left(F_{(5,1125)}=3.363, \quad P=0.009\right) \quad$ and group $\left(F_{(2,225)}=4.647\right.$, $P=0.011)$ with no interaction between emotion and group $(P=0.21)$. The corrected mean criterion value for the remitted depression group was lower (i.e. they had greater bias to identify emotions) than that for the control group and the currently depression group (Table 2, online Table DS3). The largest effects were seen for the negative emotions anger and sadness (online Fig. DS2).

\section{Effect of medication on emotion recognition}

As shown in Table 1, about half of the currently depressed group and just under a fifth of the remitted depression group were receiving antidepressant pharmacotherapy. The participants taking antidepressants ('medicated') had a similar gender ratio to the control group $\left(\chi^{2}(2)=0.4130, P=0.81\right)$, but there was a greater proportion of women in the unmedicated currently depressed $(86 \%)$ and remitted depression $(83 \%)$ groups than in the control group $\left(57 \% ; \chi^{2}(2)=15.7907, P<0.001\right)$. The medicated depressed participants were significantly older than all the other groups (mean 44.2 years, $P \leqslant 0.03$ ). There was no significant difference in mean MADRS scores between medicated and unmedicated currently depressed (25.6 v. 22.8, $P=0.16)$ or remitted depressed (3.5 v. 3.6, $P=0.91$ ) participants; however, medicated participants had experienced a greater mean number of lifetime episodes of depression than those who were unmedicated (depressed 7.1 v. 5.2, $P=0.016$; remitted depressed 4.0 v. 2.8, $P=0.026)$.

The effects of medication on emotion recognition are shown in Fig. 2 For accuracy (Fig. 2(a)), ANCOVA showed significant effects of emotion $\left(F_{(5,1115)}=11.276, P<0.001\right)$ and group $\left(F_{(4,223)}=4.146, P=0.003\right)$, with no interaction between emotion and group $(P=0.18)$. Unmedicated currently depressed participants tended to have reduced accuracy compared with controls, whereas unmedicated participants in the remitted depression group had greater accuracy, with the pattern for individual emotions similar to that seen in the whole group analysis. Medicated participants did not differ from controls. For discrimination (Fig. 2(b)), ANCOVA showed significant effects of emotion $\left(F_{(5,1115)}=25.906, P<0.001\right)$ and group $\left(F_{(4,223)}=3.528, P=0.008\right)$ with no interaction between emotion and group $(P=0.10)$. Unmedicated currently depressed participants had reduced discrimination compared with the control and unmedicated remitted depression groups; as with accuracy, the pattern for individual emotions was similar to that seen in the whole group analysis. Medicated participants did not differ from controls. For bias (Fig. 2(c)), ANCOVA showed significant effects of emotion $\left(F_{(5,1115)}=3.427, P<0.05\right)$ and group $\left(F_{(4,223)}=3.587, P=0.007\right)$ with no interaction between emotion and group $(P=0.28)$. Unmedicated participants in the remitted depression group had increased bias (lower criterion) compared with controls and unmedicated participants in the currently depressed group, with the pattern for individual emotions similar to that seen in the whole group analysis. Medicated participants did not differ from controls.

\section{Discussion}

The main findings in this study are that participants whose depression was in remission correctly identified a greater number 
Control

Depressed, unmedicated

Depressed, medicated
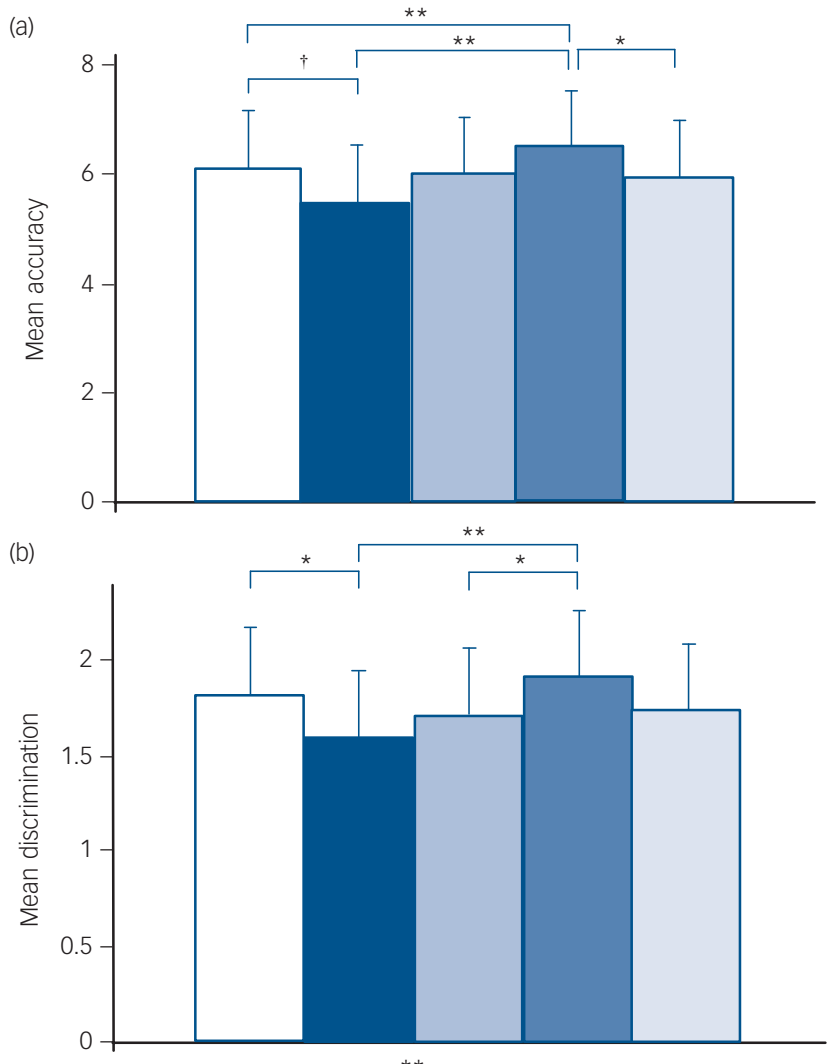

(c)

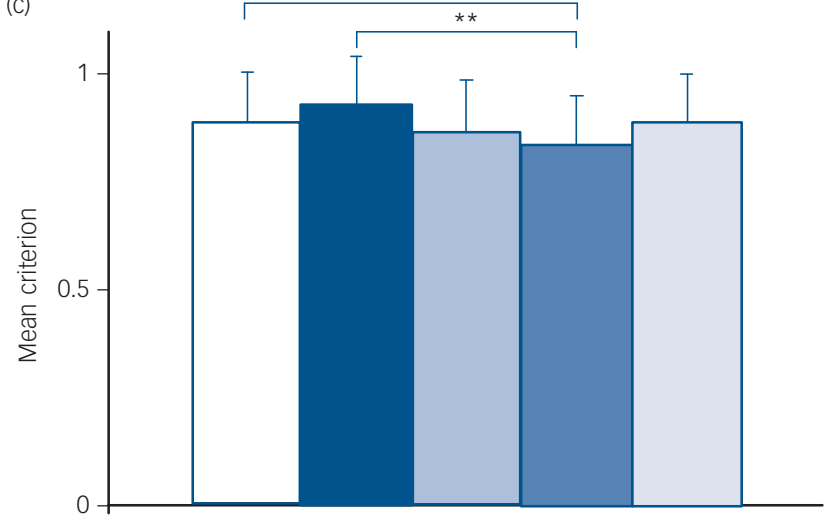

All emotions

Fig. 2 Face emotion recognition categorised by group and medication status.

Values are age- and gender-corrected means plus standard deviations. (a) Accuracy of recognition of face emotions $\times$ group. (b) Discrimination of face emotions $\times$ group. (c) Bias towards identifying face emotions $\times$ group (lower criterion indicates greater bias). ${ }^{\dagger} P<0.1 ;{ }^{*} P<0.05 ;{ }^{* \star} P<0.01$.

of face emotions than did controls and those currently depressed owing to increased bias in identifying the presence of emotion, whereas participants with current depression had impaired accuracy owing to decreased discrimination as to whether an emotion was present. We did not directly examine altered bias or discrimination between different emotions, but the lack of significant emotion $\times$ group interactions does not suggest important emotion-specific effects, contrary to our specific hypothesis about the recognition of happiness. Nevertheless, the size of the effect did appear to be greatest for mood-relevant emotions, being most pronounced for the negative emotions of anger, fear and sadness. Group differences were apparent only in unmedicated participants, with those taking antidepressants having similar accuracy, discrimination and bias to controls, independent of mood state.

\section{Effects of gender and age}

Women have higher rates of depression than men, with the most consistent evidence for the reasons behind this suggesting intrapsychic and psychosocial factors including gender role socialisation and response style (related to rumination). ${ }^{18}$ Increased sensitivity to detecting face emotions, particularly negative ones, could potentially contribute to increased vulnerability to depression through effects on social interaction or self-identification with emotional states. ${ }^{2}$ Previous studies of gender effects on face emotion recognition have usually, ${ }^{19}$ but not always, ${ }^{20}$ supported greater emotion recognition accuracy in women. The largest study to date in 1000 healthy individuals used an internet-based face emotion recognition test. ${ }^{21}$ It found similar results to our study, with overall higher accuracy for explicit emotion identification and faster reaction times in women compared with men, ${ }^{21}$ findings driven by negative expressions. Our results support the hypothesis that women are more 'tuned in' to negative facial expressions than men (although we did not demonstrate selectivity for negative emotions). This could potentially contribute to the increased vulnerability to depression seen in women, but the size of the effect is small and it is likely only to have a role in interaction with other factors. ${ }^{18}$ Our findings are also broadly consistent with a recent meta-analysis of the effect of age in the adult population, showing a general decline in face emotion recognition accuracy with age, greatest for negative emotions but with a trend to increasing accuracy in recognition of disgust. ${ }^{22}$

\section{Effect of depression history and current depression on recognising facial emotion}

Two previous smaller studies of patients with remitted depression have shown only isolated differences from controls in accuracy of face emotion recognition, with one study showing increased recognition of fear, ${ }^{8}$ and the other of disgust but not other emotions. ${ }^{9}$ Using signal detection analysis we found an overall increase in bias towards identifying emotions which appeared to be largely driven by results for mood-relevant emotions with no increased bias for disgust or surprise. Taken together with two studies of never-depressed participants with a positive first-degree family history of depression that found no alteration in face emotion recognition accuracy, ${ }^{23,24}$ these results suggest that increased bias for identifying emotional expressions may be a consequence of having experienced depression (i.e. a scar) rather than a pre-existing vulnerability. We did not find any significant emotional valence effect (i.e. no group $\times$ emotion interaction) although the findings were numerically greater for negative emotions. It is possible that past depression increases bias to identifying or labelling emotions generally rather than negative emotions specifically but this cannot be resolved from our data. Bouhuys et al found that patients with remitted depression who relapsed identified more emotions from schematic faces (especially ambiguous negative faces) than those who did not, ${ }^{25}$ providing some support that this bias might be a mechanism contributing to vulnerability to depressive relapse.

A striking - but at first sight puzzling - feature of our results is the opposite findings in currently depressed participants 
compared with the remitted depression group in their accuracy of emotion recognition; signal detection analysis indicating different mechanisms underlying the two effects, with increased bias in the former and decreased discrimination in the latter. The literature on negative emotional bias in depression reports both increased attention and facilitated processing of negative stimuli, and reduced discrimination and withdrawal or avoidance from them. ${ }^{26}$ The apparent contradictions are probably related to methodology and the type and context of stimulus presentation. Our finding of generally reduced discrimination of face emotion associated with current depression is consistent with many, ${ }^{4-6,27-30}$ but not all, ${ }^{26,31}$ studies. Using face emotion stimuli is likely to introduce social and empathic elements in addition to valence, and one explanation for reduced recognition of face emotions may be that depressed people detach (or withdraw) from the emotions of others. Consistent with this, they were found to be less able to describe emotions in others (but not in themselves) when presented with interactive scenes requiring assignment of emotion to the participants. ${ }^{32}$ Brain imaging techniques have consistently shown that depressed patients have increased amygdala activation to negative face emotions, ${ }^{33}$ which is likely to be due to increased early processing of negative stimuli. Decreased identification of the emotion may reflect a higher-level failure to link the perception and relevant knowledge about the emotion. Our findings emphasise the need to be specific about the exact nature of emotional bias being investigated, because there does not appear to be a global negative bias in depression independent of stimulus nature and context and task demands.

\section{Effects of medication}

It has recently been proposed that antidepressants work by modulating affective processing rather than by a direct effect on mood, ${ }^{10}$ and in support of this we found in a previous study that early increase in the recognition of morphed happy faces after 2 weeks of antidepressant treatment predicted symptomatic improvement at 6 weeks. $^{34}$ In our study medicated patients (irrespective of mood state) had similar face emotion recognition to controls, and currently depressed participants did not differ in their severity of depression regardless of whether they were taking medication. One interpretation is that antidepressants normalise face emotion recognition independent of mood state. This supports the hypothesis that antidepressants alter emotional processing rather than having direct effects on mood. This alteration could then promote or trigger the process of improvement, but only in receptive individuals, which may help explain why only half of patients with depression respond in clinical trials of antidepressants. ${ }^{35}$ In addition, an antidepressant-induced reduction in bias towards emotional face recognition in people with remitted depression could plausibly be a mechanism contributing to protection against depressive relapse. ${ }^{35}$

\section{Methodological considerations}

The strengths of this study are the relatively large number of well-characterised participants recruited to the control and remitted depression groups, with the majority of those in remission being drug-free and with a low current level of symptoms. However, the smaller than planned number of participants with current depression reduced the power to detect group differences; we were also not able to match for age or gender ratio in recruiting the groups and had to control for these statistically. In addition, the cross-sectional design means that we cannot exclude the possibility that confounds unrelated to depression history or state explain the group differences. Nevertheless, our findings are generally consistent with reported research, and the magnitude of the age difference between the control group and the remitted depression group in particular is unlikely to be biologically important. The results for the effect of antidepressant medication also need to be replicated as numbers were small which reduced statistical power, participants were not randomised and factors apart from medication could explain the differences between those taking or not taking medication. This could include illness factors such as number of episodes or overall severity of illness. Finally, the emotion recognition task, although based on that by Harmer et $a l,{ }^{15}$ was restricted to three mood intensity levels and had a longer stimulus presentation time ( $1 \mathrm{~s} v .0 .5 \mathrm{~s})$ in order to make it less effortful for the currently depressed participants. Caution is therefore needed when comparing results derived from the two versions of the task.

In summary, we found that depression is associated with abnormalities in face emotion recognition which differ according to current mood state, with decreased accuracy and discrimination in currently depressed participants and increased accuracy and bias in those with a history of depression who are currently well. The increased bias to recognise emotions in remitted depression is a possible mechanism of susceptibility to depression, although the effect was small. Further studies are required to determine whether this is a pre-existing vulnerability or a result of having been depressed. The lack of abnormality in face emotion recognition seen in those treated with antidepressants may relate to these drugs' known modulation of emotional processing and could contribute to their ability to protect against relapse.

Ian M. Anderson, MBBS, MD, MRCP, FRCPsych, Neuroscience and Psychiatry Unit, University of Manchester; Clare Shippen, MBChB, Trafford Healthcare National Health Service Trust, Trafford General Hospital, Davyhulme; Gabriella Juhasz, MD, PhD, Diana Chase, BSc, PhD, Emma Thomas, BSc, PhD, Neuroscience and Psychiatry Unit, University of Manchester; Darragh Downey, MSC, PhD, Imaging Science and Biomedical Engineering, University of Manchester; Zoltan G. Toth, MSC, Faculty of Life Sciences, University of Manchester; Kathryn Lloyd-Williams, BSC, Rebecca Elliott, PhD, J. F. William Deakin, MBChB, PhD, FRCPsych, FMedSCi, Neuroscience and Psychiatry Unit, University of Manchester, Manchester, UK

Correspondence: Professor lan Anderson, Neuroscience and Psychiatry Unit school of Community Based Medicine, Stopford Building, Oxford Road, Manchester M13 9PT, UK. Email: ian.anderson@manchester.ac.uk

First received 24 Jan 2010, final revision 22 Aug 2010, accepted 28 Sep 2010

\section{Funding}

Funding for this study was provided by an EU Framework 6 Integrated Programme Grant (NewMood; LSHMCT-2004-503474).

\section{Acknowledgements}

We are grateful for the facilities provided by the Wellcome Trust Clinical Research Facility, Manchester.

\section{References}

1 Ekman P. Facial expression and emotion. Am Psychol 1993; 48: 384-92.

2 Adolphs R. Recognizing emotion from facial expressions: psychological and neurological mechanisms. Behav Cogn Neurosci Rev 2002; 1: 21-62.

3 Leppanen JM. Emotional information processing in mood disorders: a review of behavioral and neuroimaging findings. Curr Opin Psychiatry 2006; 19: 34-9.

4 Rubinow DR, Post RM. Impaired recognition of affect in facial expression in depressed patients. Biol Psychiatry 1992; 31: 947-53.

5 Mikhailova ES, Vladimirova TV, Iznak AF, Tsusulkovskaya EJ, Sushko NV. Abnormal recognition of facial expression of emotions in depressed patients with major depression disorder and schizotypal personality disorder. Biol Psychiatry 1996; 40: 697-705. 
6 Surguladze SA, Young AW, Senior C, Brébion G, Travis MJ, Phillips ML, et al Recognition accuracy and response bias to happy and sad facial expressions in patients with major depression. Neuropsychology 2004; 18: 212-8.

7 Mathews A, MacLeod C. Cognitive vulnerability to emotional disorders. Annu Rev Clin Psychol 2005; 1: 167-95.

8 Bhagwagar Z, Cowen PJ, Goodwin GM, Harmer CJ. Normalization of enhanced fear recognition by acute SSRI treatment in subjects with a previous history of depression. Am J Psychiatry 2004; 161: 166-8.

9 Hayward G, Goodwin GM, Cowen PJ, Harmer CJ. Low-dose tryptophan depletion in recovered depressed patients induces changes in cognitive processing without depressive symptoms. Biol Psychiatry 2005; 57: 517-24.

10 Harmer CJ, Goodwin GM, Cowen PJ. Why do antidepressants take so long to work? A cognitive neuropsychological model of antidepressant drug action. Br J Psychiatry 2009; 195: 102-8.

11 Spitzer RL, Williams JB, Gibbon $M$, First MB Structured Clinical Interview for DSM-III-R - Patient Edition (SCID-P, version 1.0). American Psychiatric Press, 1990

12 Montgomery SA, Åsberg M. A new depression scale designed to be sensitive to change. Br J Psychiatry 1979; 134: 382-9.

13 Snaith RP, Baugh SJ, Clayden AD, Husain A, Sipple MA.The Clinical Anxiety Scale: an instrument derived from the Hamilton Anxiety Scale. Br J Psychiatry 1982; 141: 518-23.

14 Ammons R, Ammons C. The Quick Test provisional manual. Psychol Reports (monograph supplement I-VII) 1962; 11: 111-61.

15 Harmer CJ, Perrett DI, Cowen PJ, Goodwin GM. Administration of the betaadrenoceptor blocker propranolol impairs the processing of facial expressions of sadness. Psychopharmacology (Berl) 2001; 154: 383-9.

16 Ekman P, Friesen WV. Pictures of Facial Affect. Consulting Psychologists, 1976.

17 Macmillan NA, Creelman CD. Detection Theory: A User's Guide. Erlbaum, 2004.

18 Kuehner C. Gender differences in unipolar depression: an update of epidemiological findings and possible explanations. Acta Psychiatr Scand 2003; 108: 163-74

19 McClure EB. A meta-analytic review of sex differences in facial expression processing and their development in infants, children, and adolescents. Psychol Bull 2000; 126: 424-53.

20 Rahman Q, Wilson GD, Abrahams S. Sex, sexual orientation, and identification of positive and negative facial affect. Brain Cogn 2004; 54 $179-85$

21 Williams LM, Mathersul D, Palmer DM, Gur RC, Gur RE, Gordon E. Explicit identification and implicit recognition of facial emotions: I. Age effects in males and females across 10 decades. J Clin Exp Neuropsychol 2009; 31 257-77.
22 Ruffman T, Henry JD, Livingstone V, Phillips LH. A meta-analytic review of emotion recognition and aging: implications for neuropsychological models of aging. Neurosci Biobehav Rev 2008; 32: 863-81.

23 Le Masurier M, Cowen PJ, Harmer CJ. Emotional bias and waking salivary cortisol in relatives of patients with major depression. Psychol Med 2007; 37 403-10.

24 Mannie ZN, Bristow GC, Harmer CJ, Cowen PJ. Impaired emotional categorisation in young people at increased familial risk of depression. Neuropsychologia 2007; 45: 2975-80.

25 Bouhuys AL, Geerts E, Gordijn MC. Depressed patients' perceptions of facial emotions in depressed and remitted states are associated with relapse: a longitudinal study. J Nerv Ment Dis 1999; 187: 595-602.

26 Gollan JK, Pane HT, McCloskey MS, Coccaro EF. Identifying differences in biased affective information processing in major depression. Psychiatry Res 2008: 159: 18-24.

27 Csukly G, Czobor P, Szily E, Takács B, Simon L. Facial expression recognition in depressed subjects: the impact of intensity level and arousal dimension. J Nerv Ment Dis 2009; 197: 98-103.

28 Gur RC, Erwin RJ, Gur RE, Zwil AS, Heimberg C, Kraemer HC. Facial emotion discrimination: II. Behavioral findings in depression. Psychiatry Res 1992; 42: $241-51$

29 Hale WW, Jansen $\mathrm{JH}$, Bouhuys A, van den Hoofdakker RH. The judgement of facial expressions by depressed patients, their partners and controls. J Affect Disord 1998; 47: 63-70.

30 Langenecker SA, Bieliauskas LA, Rapport L, Zubieta JK, Wilde EA, Berent S. Face emotion perception and executive functioning deficits in depression. J Clin Exp Neuropsychol 2005; 27: 320-33.

31 Suslow $T$, Junghanns $K$, Arolt $V$. Detection of facial expressions of emotions in depression. Percept Mot Skills 2001; 92: 857-68.

32 Donges US, Kersting A, Dannlowski U, Lalee-Mentzel J, Arolt V, Suslow T. Reduced awareness of others' emotions in unipolar depressed patients. J Nerv Ment Dis 2005; 193: 331-7.

33 Fales CL, Barch DM, Rundle MM, Mintun MA, Snyder AZ, Cohen JD, et al. Altered emotional interference processing in affective and cognitive-control brain circuitry in major depression. Biol Psychiatry 2008; 63: 377-84.

34 Tranter R, Bell D, Gutting P, Harmer C, Healy D, Anderson IM. The effect of serotonergic and noradrenergic antidepressants on face emotion processing in depressed patients. J Affect Disord 2009; 118: 87-93.

35 Anderson IM, Ferrier IN, Baldwin RC, Cowen PJ, Howard L, Lewis G, et al. Evidence-based guidelines for treating depressive disorders with antidepressants: a revision of the 2000 British Association for Psychopharmacology guidelines. J Psychopharmacol 2008; 22: 343-96. 